\title{
Estimation of Foliar Pigment Concentration in Floating Macrophytes using Hyperspectral Vegetation Indices
}

\author{
Cameron Proctor ${ }^{1}$, Yuhong $\mathrm{He}^{2}$ \\ Department of Geography, University of Toronto Mississauga, 3359 Mississauga Road N, \\ William G. Davis Bldg, L5L 1C6, Mississauga, Ontario, Canada \\ Department Fax: (905) 828-5273 \\ 1cameron.proctor@utoronto.ca \\ 2yuhong.he@utoronto.ca
}

\begin{abstract}
Foliar pigment concentrations of chlorophylls and cartenoids are important indicators of plant physiological status, photosynthesis rate and net primary productivity. Although the utility of hyperspectral derived vegetation indices for estimating foliar pigment concentration has been documented for many vegetation types, floating macrophytes have not been assessed despite their ecological importance. This study surveyed 39 wetland species (12 floating macrophytes (FM), 8 grasses/sedges/rushes (GSR) and 19 herbs/wildflowers (HWF)) to determine whether foliar pigments concentrations could be estimated from hyperspectral reflectance. Hyperspectral reflectance of samples was recorded using an ASD FieldSpec3 Max portable spectroradiometer with the plant probe attachment or via a typical laboratory setup. A semi-empirical relationship was established using either a linear, second-degree polynomial or logarithmic function between 13 candidate vegetation indices and Chl-a, Chl-b, Car and Chl-a+b pigment concentrations. Vegetation indices R-M, CI-Red and MTCI were strongly correlated with foliar pigment concentrations using a linear fitting function. Chl-a+b and Chl-b concentrations for all samples were reasonably estimated by the R-M index $\left(R^{2}: 0.66\right.$ and 0.64$)$, although Chl-a and Car concentration estimates using CI-Red were weaker $\left(\mathrm{R}^{2}: 0.63\right.$ and 0.51$)$. Regression results indicate that pooled samples to estimate individual foliar pigments were less correlated than when each type of vegetation type was treated separately. For instance, Chl-a+b was best estimated by CI-Red for FM $\left(\mathrm{R}^{2}: 0.80\right)$, MTCI for HWF ( $\left.\mathrm{R}^{2}: 0.77\right)$ and R-M for GSR $\left(\mathrm{R}^{2}: 0.67\right)$. Although floating macrophytes feature unique adaptions to their aquatic environment, their foliar pigment concentrations and spectral signatures were comparable to other wetland vegetation types. Overall, vegetation indices that exploit the red-edge region were a reasonable compromise that had good explanatory power for estimation of foliar pigments across the sampled wetland vegetation types with CI-Red the best suited index for floating macrophytes.
\end{abstract}

Keywords: floating macrophyte, chlorophyll, vegetation indices, pigment concentration estimation, wetland vegetation types 


\subsection{Introduction.}

Foliar photosynthetic pigments are the dominant influence upon the amount of solar radiation absorbed by leaves. Of these, chlorophyll-a (Chl-a) and chlorophyll-b (Chl-b) absorb the greatest fraction of photosynthetically active radiation and supply the majority of the energy for the reaction of photosynthesis (Ustin et al. 1998). Hence, foliar concentrations of Chl-a and Chl-b (Chls) often control the carbon fixed per unit radiation intercepted and are strongly related to net primary productivity (Dawson et al. 2003). Other important photosynthetic components include the carotenoids (Cars), which are essential structural components of the photosynthetic antenna and reaction centre complexes (Bartley and Scolnik 1995). Cars have dual photosynthetic and photoprotective roles, coincidentally contributing energy to photosynthesis and dissipating excess energy through the xanthophyll cycle to protect the reaction centres.

Since foliar concentrations of Chls and Cars are linked to the photosynthesis rate (Daughtry et al. 2000) quantifying their concentration at the leaf and canopy levels has a range of applications including indicating the plants physiological status (le Maire et al. 2004). Foliar Chls concentration also provides an indirect estimate of plant nutrient status since their molecular structure incorporates a large proportion of total leaf nitrogen (Moran et al. 2000). Quantifying individual pigment concentrations are also valuable, since individual pigments respond differently to changing environmental conditions. For instance, the ratio of Chl-a to Chl$\mathrm{b}$ increases during leaf senescence which is induced by the decline in the daily photoperiod (Fang et al. 1998). Hence, individual measures of foliar pigment concentrations can provide useful insights into plant-environment interactions (Richardson et al. 2002).

Traditional wet chemistry techniques for measuring foliar pigment concentrations require destructive sampling involving extracting pigments with a solvent and subsequent spectrophotometric analysis. These procedures are costly, laborious and hence can only provide limited spatial coverage (Gitelson et al. 2005). Alternatively, measures of reflected radiation are a non-destructive method for quantifying pigment concentration due to the unique spectral absorbance features of foliar pigments manifesting as the dominant constituents of leaf reflectance. Many studies have shown that surface reflectance of intact leaves are directly correlated with leaf chemical composition (Jacquemoud et al. 1996) and surface reflectance is often used as indicators of photosynthetic function in the remote sensing of vegetation (Field et al. 1994). Provided hyperspectral data of sufficient resolution is available (usually bandwidths of 10nm or less (Broge and Mortensen 2002)), Chls and Cars concentration can be estimated for a diverse range of vegetation types based on the establishment of a semi-empirical relationship between laboratory measured pigment concentration and hyperspectral reflectance.

As hyperspectral data volumes are quite large and contain many collinear bands, the whole hyperspectal spectrum is often reduced to a smaller feature space. Feature selection approaches have included principal components (Yao and Tian 2003), factor analysis (Coops et al. 2002), artificial neural networks (Chen et al. 2007) and stepwise multiple regression (Osborne et al. 2002). In addition, vegetation indices exploiting two to four bands are often used as they are computationally simple and are reasonably applicable to estimate foliar pigments at the leaf scale (Sims and Gamon 2002, Gitelson et al. 2003, le Maire et al. 2004), and canopy scale (Thenkabail et al. 2002, Dash and Curran 2004), while NDVI also outperformed a partial least squares regression model based on the whole spectrum for winter wheat (Hansen and Schjoerring (2003).

Floating macrophytes are an important component of wetland ecosystems as they foster biological diversity and their high growth rates provide an abundant foodstuff that many species 
depend upon (Chapman et al. 2001). They also filter excess nutrients and thus reduce the onset and severity of eutrophication. Certain species also hyperaccumulate toxic trace elements and thus play a considerable role in wastewater treatment, biomonitoring of pollutants and phytoremediation (Outridge and Noller 1991, Rahman and Hasegawa 2011). Conversely, floating macrophytes can also interfere with biogeochemical processes, ecological functioning and human utilization of water bodies as a consequence of their prolific productivity (Kateregga and Sterner 2007). For instance, dominant stands of Trapa natans often induce hypoxic conditions. Reduced dissolved oxygen concentrations cause stress for juveniles in key breeding grounds (Burlakova and Karatayev 2007) and may induce increased atmospheric emission of carbon dioxide and methane, becoming a net greenhouse gas source over the long term (Pierobon et al. 2010). However, a comprehensive examination of floating macrophytes as regulators of trace gasses has not been conducted and many questions regarding their biogeochemical affects remain.

In addition to their varied importance, floating macrophytes feature a variety of unique morphological adaptions to the aquatic environment. Many of these adaptions reflect the species different ecological niches, nutrient acquisition strategies or are related to buoyancy or protection from wave action. These adaptations influence the spectral reflectance at the species level, where considerable variation has been documented between floating macrophytes (Anderson 1995). For instance, Khanna et al. (2011) exploits biophysiological differences to differentiate between three mat-forming floating macrophytes in the Sacramento-San Joaquin Delta. In spite of the species expressing a wide range of phenotypic variability, a decision trees classifier could distinguish each species with 71-88\% accuracy due, in part, to variations in short-wave infrared, red edge index and near-infrared reflectance. Tilley et al. (2003) also documents differing average leaf hyperspectral reflectance in the emergent macrophytes Typha latifolia and B. frutescens, where the blue and red wavebands had a strong negative correlation to water column total ammonia. The negative correlation indicates there was more chlorophyll present when ammonia levels were higher and that B. frutescens responded more strongly than $\mathrm{T}$. latifolia, likely related to its greater nutrient uptake ability. Aside from plant response environmental stimuli, reflectance is also sensitive to specialized plant adaption's (e.g. waxy leaf surfaces in desert plants increase reflectance to guard against photo-inhibition of photosynthesis (Robinson et al. 1993)) and can vary independently of pigment concentration (Sims and Gamon 2002). Hence, floating macrophyte adaptions to the aquatic environment may introduce confounding factors that cause both hyperspectral reflectance and pigment concentrations to vary to a greater degree between floating macrophyte species that between species of other vegetation types.

Despite their unique traits, floating macrophytes have received less attention than other vegetation types, perhaps due to the logistical challenges posed by the wetland environment (Lee and Lunetta 1996). The utility of several vegetation indices for foliar pigment estimation has been documented for many other types of vegetation including crops (Zarco-Tejada et al. 2005), forests (Sampson et al. 2000) and heterogeneous grasslands (Darvishzadeh et al. 2008). Nonetheless, previous research is primarily empirical. The developed relationships are unique to a specific vegetation type under defined environmental conditions and are thus non-transferable. Consequently, to meet the requirements related to estimation accuracy and consistency, there is a need for the identification of specific vegetation indices that are sensitive exclusively to floating macrophytes. In addition, it is desirable to avoid the need for a semi-empirical relationship for each wetland vegetation type. However, no studies have assessed the difference in explanatory power between hyperspectral reflectance and pigment concentrations for all wetland species or separate wetland vegetation types. 

hyperspectral data for their explanatory power to estimate laboratory extracted foliar pigment concentration from all species and independently for various wetland vegetation types. This study seeks to address two questions: (1) to what extent do floating macrophyte pigment concentrations differ from other wetland vegetation types, and (2) which vegetation indices can best estimate floating macrophyte foliar photosynthetically active pigment concentrations (Chl-a, Chl-b, Car, Chl-a+b).

\subsection{Methodology}

\subsection{Site Description and Sample Collection}

Leaves from 39 wetland species (12 floating macrophytes (FM), 8 grasses/sedges/rushes (GSR) and 19 herbs/wildflowers (HWF)) were collected from two plant nurseries and from two field sites near Toronto, Ontario (Table 1). Site one was Cranberry marsh (43.844 ${ }^{\circ} \mathrm{N}, 78.965$

${ }^{\circ} \mathrm{W}$ ), a 40 hectare provincially significant coastal wetland along the northern section of the Lake Ontario shoreline between Ajax and Oshawa. Although a coastal wetland, Cranberry Marsh water levels were controlled prior to 2001. After 2001, a low-high water level cycle was reestablished to promote regeneration of the vegetation community. Site two was the wetlands at the outflow of the Rough River into Lake Ontario near Rouge Beech Park (43.794 ${ }^{\circ} \mathrm{N}, 79.121$ $\left.{ }^{\circ} \mathrm{W}\right)$ along the border of Toronto and Pickering. The outflow of the Rough River meanders through dense cattails, creating several pockets of slow moving water where various floating macrophytes have taken advantage of the stagnant conditions. In addition to the specimens collected in the field, various invasive and native species that were not present at the field sites were acquired from two local plant nurseries in Brampton and Ajax. Multiple samples were taken for certain species due to leaf age, presence at multiple sites or due to heterophyllous morphologies. In total 48 samples were acquired, 17 FM, 9 GSR and 22 HWF.

Field work was conducted August 4th for Cranberry Marsh and August 11th and 18th for Rough Park during the summer of 2012. Plant nursery samples were collected the same day. Samples collected in the field and from plant nurseries were packaged in an opaque plastic bag with air holes and stored in a cooler for transportation from the fields to the laboratory for subsequent in-vivo measurements. All samples were processed within 24 hours. Samples were washed with distilled water and dried with a paper towel to remove any dirt and debris from the vegetation.

\subsection{Hyperspectral Measurements}

Leaf level spectral measurements were taken in the lab from 10 leaves of each sample with five replicate measurements, using a FieldSpec3 Max portable spectroradiometer (Analytical Spectral Devices, Inc., Boulder, CO). The FieldSpec3 uses one 512 element Si photodiode array to measure between 350-1000 $\mathrm{nm}$ and two InGaAs photodiodes to measure between 1000-2500 nm with an approximate spectral resolution of 3 nm @ $700 \mathrm{~nm}$ and $10 \mathrm{~nm} @$ 1400/2100 nm. Hyperspectral measurements were taken using the plant probe and leaf clip attachments to control the illumination geometry and standardized the measurement conditions. The sample was illuminated by the plant probe's halogen lamp (3.825 Volt, $4.05 \mathrm{Watt})$ which was internally set at a constant distance resulting in field of view of $10 \mathrm{~mm}$. Prior to each 
reflectance measurement, the FieldSpec3 was optimized and the radiance of the illuminated back face panel without sample was recorded for normalization of the target measurements.

Hyperspectral measurements of Azolla filiculoides, Salvinia molesta, Lemna minor and Spirodela polyrhiza could not be taken by the plant probe due to the small leaf size (Wolffia arrhiza: $0.5 \mathrm{~mm}$ to Salvinia molesta: $2 \mathrm{~cm}$ ). For these species, hyperspectral measurements were taken using an ASD Pro Lamp (14.5 Volt, 50 Watt) designed for indoor lab diffuse reflectance measurements and the FieldSpec 3 fore optic, both placed at $20 \mathrm{~cm}$ height at a $45^{\circ}$ angle off nadir in perpendicular positions facing a target black surface. Each species was placed in a standard container filled with distilled water such that $100 \%$ areal coverage two times the fore optic field of view was achieved. The sample container was rotated and the vegetation mixed prior to each of 10 measurements with five replicates per measurement. Prior to each reflectance measurement, the radiance of a Spectralon white reference panel (Labsphere, Inc., North Sutton, $\mathrm{NH}$ ) was recorded for normalization of the target measurements. To ensure the compatibility between the plant probe and the lab setup methods, hyperspectral measurements using both methods were conducted for all samples obtained from Cranberry Marsh. A visual comparison indicated that the lab setup yielded comparable spectral signatures to the plant probe approach.

Recorded spectra were processed using the RS3 software (Analytical Spectral Devices, Inc., Boulder, CO). Splice correction was applied to remove artifacts associated with detector differences at 1000 and $1800 \mathrm{~nm}$. The recorded spectra were averaged for each sample.

\subsection{Derivation of Vegetation Indices}

Of the $>40$ published vegetation indices, a subset of the available indices that are sensitive to pigment concentration and generally unresponsive to leaf area index and soil background were selected for this study (Table 2). Care was taken to select indices that exploit different spectral regions such as the position of the red-edge, the reflectance change at the rededge, the depth of chlorophyll absorption in the visible region, the contrast between red and near infrared (NIR) regions and reflectance in the visible region due to xanthophylls cycle pigments. All selected hyperspectral vegetation indices were calculated from mean reflectance.

\subsection{Foliar Pigment Extracts}

For pigment determination, two extracts per sample were processed $(n=96)$. Leaves were removed from the stem, roots and remaining plant matter with a scalpel. Leaves were cut into small pieces and $120 \mathrm{mg}$ fresh weight was extracted in $100 \%$ acetone $(0.7 \mathrm{~mL})$ and $30 \mathrm{mg}$ sodium bicarbonate. Samples were mixed in a vortex for 20 minutes and centrifuged at 14,000g for six minutes to separate the natant from the pellet. After two hours on ice in an opaque box, the natant was extracted and the pellet re-extracted in acetone a further two times for a combined extraction of $2.1 \mathrm{~mL}$ in $100 \%$ acetone. Chl-a, Chl-b, Car and Chl-a+b were then quantified using a spectrophotometer tuned to the absorbance of the liquid extracts at 470, 645 and $662 \mathrm{~nm}$. Between three and six replicate spectrophotometer reading per sample were taken. The pigment concentrations were calculated using the specific absorption coefficients provided by Porra et al. (1989). The Chl-a, Chl-b, Car and Chl-a+ b concentration per extract was calculated as the mean of all replicates. The concentration per sample was taken as the mean of the two extracts.

\subsection{Statistical Analysis}


To test whether Chl-a, Chl-b, Car and Chl-a+b could be estimated regardless of vegetation type, regression was performed on all sample data (class ALL) for each of the 13 vegetation indices. Regression was additionally performed for all samples belonging to the three vegetation types (Table 1). In all cases, linear, second-degree polynomial and logarithmic functions were fitted to the measured pigment concentration as the dependent variable and the hyperspectral vegetation index as the independent variable. The fitted functions were obtained by the least square adjustment method using the $\mathrm{R}$ software package and coefficient of variation of the root mean square error (cvRMSE) were coincidentally calculated to evaluate the explanatory strength of the fitted function. The vegetation indices that yielded the lowest cvRMSE and highest $\mathrm{R}^{2}$ were deemed preferred for foliar pigment concentration estimation. cvRMSE was selected as it less sensitive than root mean square error to variations in the range and foliar pigment concentrations are of different scales.

\subsection{Results}

The range of pigment concentration for ALL samples is $0.017-0.306 \mathrm{ug} / \mathrm{mg}$ for Chl-a, 0.008-0.228 ug/mg for Chl-b, 0.006-0.099 ug/mg for Car and 0.025-0.512 ug/mg for Chl-a+b. Foliar concentrations of Chl-b and Car are typically lower than Chl-a in most plant species due to their secondary and auxiliary roles in photosynthesis (Blackburn 1998). All foliar pigment concentrations are highly correlated. Chl-a concentration has a $\mathrm{R}^{2}$ of 0.91 with Chl-b using a linear fitting function and $a \mathrm{R}^{2}$ of 0.90 with Car and $a \mathrm{R}^{2}$ of 0.97 with Chl-a+b respectively.

Mean foliar concentrations of individual pigments vary between vegetation types (Table 3). Although FM and HWF pigment concentrations have a similar range and variability (Figure 1), FM has the lowest mean pigment concentration for all pigment types, while HWF has the highest mean Chl-a and Car concentrations. GSR has the highest mean Chl-b and Chl-a+b concentration. However, pigments concentrations of GSR are more variable than FM or HWF, with the strongest variability in GSR Chl-b concentration (mean $0.078 \mathrm{ug} / \mathrm{mg}$, standard deviation $0.076 \mathrm{ug} / \mathrm{mg}$ ). The variability is partially due to certain GSR species that have high Chl-a concentrations compared to all other species and correspondingly high Chl-b concentrations. Hence, the mean Chl-a/Chl-b ratio is considerably lower for GSR (2.78) when compared to FM (3.07) and HWF (3.03), which are very similar considering the Chl-a/Chl-b ratio varies considerably.

Reflectance spectra clearly display the major absorption features indicative of chlorophyll with the typical green peak around 550nm, red-edge around $675 \mathrm{~nm}$, sill in the NIR around 750 $\mathrm{nm}$ and subsequent NIR plateau. Standard deviation of all samples mean reflectance indicates that samples primarily varied in the NIR (Figure 2). Variability in reflectance was minimal around $675 \mathrm{~nm}$ and increased along the red-edge as well as approaching the green peak. The regions of variability correspond as expected from samples varying in pigment concentration. FM species tended to have the lowest reflectance in the visible and green peak regions (e.g. Water Smartweed spectra curve in Figure 2). In terms of the red-edge regions FM species generally have a similar slope to HWF species. The slope in the red-edge is less pronounced in GSR species which tended to have high reflectance in the visible region and low to average NIR reflectance. There is considerable overlap in the shape of spectral signatures between vegetation types. Furthermore, reflectance varied considerable between species belonging to a vegetation type. For instance, Marsh Pepper Smartweed has a high NIR reflectance for a member of its vegetation type (Figure 2). 


\subsection{Relationships between vegetation indices and foliar pigment concentration}

For a given vegetation index, the performance of the three tested fitted functions are similar (Table 4). Compared to the linear regression, a log fitted function generally resulted in a decrease in $\mathrm{R}^{2}$. In contrast, utilizing a second-degree polynomial yields a slightly improved correlation in all cases. At minimum the increase in $\mathrm{R}^{2}$ is 0.01 to a maximum of 0.18 , although a $\sim 0.04$ improvement is average. The fitted curve often approximates a straight line with a weakly curved shape (Figure 3(a iii)). Thus, the gain in performance is likely due to better estimation of the values at the poles of the pigment concentration range, as is evident in the case of ALL Chl-b (Figure 3(a ii)). However, the number of data points is often sparse in the curves of the regression line and insufficient to support second-degree polynomial regression. Given that previous studies have shown a linear relationship when the chlorophyll concentration range of the samples is moderate (Gitelson et al. 2003, Gitelson et al. 2005), the linear regression is more sound, contrary to the increase in performance from a second-degree polynomial.

NDVI and HNDVI vegetation indices performed poorly for all groups regardless of pigment type (Table 4). NDVI and HNDVI likely performed poorly in predicting leaf chlorophyll content as they are partially based on NIR scattering which likely varies between species as a function of the number of cell-water interfaces within the leaf spongy mesophyll. Similarly, NGAI and OSAVI also consistently poor as they are partially based on the contrast between the NIR plateau and the green peak or red-edge. For the group of species under investigation, the PRI index is also not well correlated to any pigment concentration, possibly since the index is sensitive to rapid changes in the relative levels of xanthophyll cycle pigments (Gamon et al. 1997) and photosynthesis was not controlled post harvesting. Moderately performing vegetation indices include DD, REP, CI-Green, CARI and MCARI. Their $\mathrm{R}^{2}$ values tend to range between the mid 0.5 's and mid 0.7 's depending upon the vegetation type. For instance, REP correlated with Chl-a concentration well for HWF $\left(\mathrm{R}^{2}: 0.738\right)$ but only reasonably for FM $\left(\mathrm{R}^{2}: 0.542\right)$. The indices that consistently perform high for each vegetation type across all pigment types are R-M, CI-Red and MTCI.

Overall the $\mathrm{R}^{2}$ values between the derived hyperspectral vegetation indices and pigment concentrations for ALL samples ranged from 0.51 to 0.66 (Table 5). The R-M and CI-Red indices fitted with a linear function performed best for ALL samples with Chl-a+b and Chl-b having the strongest relationship with the former and the slightly more scattered Chl-a and Car by the latter. The performance of these indices are negligibly greater than other top performing indices such as CI-RED, MTCI.

Regression results indicate that pooled samples to estimate individual foliar pigments is less correlated than when each type of vegetation type is treated separately (Table 5). When estimated per vegetation type, the fitted functions have greater $\mathrm{R}^{2}$ values between the tested vegetation indices and the individual foliar pigments concentrations. The only exception is the Chl-b correlation is slightly lower for GSR than all pooled sampled ( $\mathrm{R}^{2}$ ALL: 0.64, GSR: 0.55), although the relative error is comparable (cvRMSE All: 0.230, GSR: 0.215), suggesting the fitted functions are approximately equal in performance. The vegetation index that yielded the best fit varies between vegetation types (Table 5). FM foliar pigments are best estimated by indices that exploit the red-edge. In all cases of FM foliar pigment estimation, CI-Red has a slight performance improvement over MTCI and R-M, on the order of 0.02 to $0.09 \mathrm{R}^{2}$. The second best performing index does vary by pigment type, with MTCI better for Chl-a and Chl-a+b and R-M better for Chl-b and Car. MTCI is also the best estimator of HWF pigment concentration for all pigments except Chl-b to which MCARI offers a $0.08 \mathrm{R}^{2}$ improvement. Lastly the correlation 
between GSR and pigment concentrations is generally lower due to the low number of data points and larger concentration range. GSR is best estimated by R-M which consistently offers a slight improvement over R-M and MTCI. The second best index is consistently CI-Red followed closely by MTCI for all pigment types.

\subsection{Discussion}

FM pigment concentrations are subtly different from other wetland vegetation types. Floating macrophyte species tend to have pigment concentrations less than terrestrial herbs, wildflowers and grasses. However, the difference between vegetation types is not as stark as has been reported between artic shrubs (Fletcher et al. 2012) and bushland or forest vegetation types (Blackburn 2007). Chl-b concentrations varied the most between vegetation types, with FM constrained to a narrower range and lower concentration than HWF or GSR (Figure 4). In general all pigment concentrations for GSR are highly variable. This variability may not be related to GSR biochemistry, but due to environmental factors. Nutrient availability and water stress can cause pigments concentrations to vary (le Maire et al. 2004). Notably the summer of 2012 was unusually warm and samples obtained from the two field sites are from exposed soils that are typically inundated. In contrast, HWF Chl-b variations appear related to differences in photosynthetic machinery. Increased levels of Chl-b are a shade adaption that permits more trapping of light energy (Kitajima and Hogan 2003). Thus, the variable Chl-b concentration is likely due to the inclusion of sun and shade species within the HWF vegetation type. Floating macrophytes are rarely shaded and the photosynthetic photon flux density at which photosynthesis is saturated is higher than $1400 \mu \mathrm{mol} \mathrm{m}^{-2} \mathrm{~s}^{-1}$ (Tsuchiya 1991). Hence, floating macrophyte species are well adapted to full sunlit conditions and thus may expend minimal resources on shade adapted photosynthetic machinery.

The variable pigment concentrations between wetland vegetation types suggest that adaptions to ecological niches play a role in determining foliar biochemistry. However, the specialized adaptions of floating macrophyte species to the aquatic environment did not cause abnormal reflectance or pigment concentrations. The hair-like strands covering the bristly surface of Salvinia fronds may have confounded the reflectance measurement, as hairs are known to increase reflectance in the visible region and occasionally the NIR region (Slaton et al. 2001) though no such effect could be distinguished. The only species that displays any sizeable disproportionality between reflectance and pigment concentration is Water Lettuce. Reflectance of Water Lettuce is higher than its pigment concentration indicates. Since Water Lettuce buoyancy is provided by it thick, air-filled leaves (the largest of any sampled species) the pigment concentration is likely reduced as these cavities consume a greater portion of the total weight.

Overall the CI-Red vegetation index fitted with a linear function performs best for estimating floating macrophyte pigment concentrations. The R-M index follows closely in performance. Both indices perform well because of their derivation from the slope of the rededge. The major calculation difference is that CI-Red determines the red-edge slope from a wider range of bandwidth approaching the red-edge inflection point and the NIR sill, whereas R-M is determined squarely within the red-edge. Although, both CI-Red and R-M perform well for estimating HWF pigment concentrations, the MTCI index achieves a slight 0.02 to 0.10 better $\mathrm{R}^{2}$. The sole exception for MTCI is for Car concentration for HWF. For this pigment, MCARI outperforms the linear MTCI $\left(\mathrm{R}^{2}: 0.545\right.$ versus 0.468$)$. In summation, the results suggest that vegetation indices based on the red-edge tend to outperform those involving the green peak. 
Indices involving the green peak (NGAI) or slightly offset of the green peak (PRI) tend to perform poorly while mixed NIR and green peak indices (CARI and MCARI) tend to perform reasonably well for certain vegetation types. In the case of Chl-a estimation, CARI and MCARI performed on par with MTCI for HWF, reasonably well for ALL, mixed for FM (CARI R ${ }^{2}$ : 0.705, MCARI R ${ }^{2}$ : 0.294) and poor for GSR (Table 4). In comparison CI-green, also involving the green peak, performs more consistently regardless of group or pigment. The $\mathrm{R}^{2}$ value of CIgreen is $\sim 0.04$ higher for each pigment compared to MTCI for HWF (e.g. MTCI R ${ }^{2}: 0.771$ for Chl-a+b versus CI-green $\mathrm{R}^{2}: 0.733$ ).

While this study documents good performance in foliar pigment estimation, extrapolating from the leaf to canopy scale involves a number of confounding factors and previous attempts to estimate canopy pigment concentrations have shown poor signal propagation between the leaf and canopy scale (Yoder and Pettigrew-Crosby 1995, Jacquemoud et al. 1996, Asner 1998, He and Mui 2010). For floating macrophytes the largest confounding factor is the likelihood of variable water inundation. The spectral signatures from leaves covered by an increasingly thick water layer will exhibit decreasing reflectance in the NIR plateau. Although plant NIR reflectance is typically flat between 800-1400n, small water absorption affects in 970 and 1180 can be present to a degree depending upon the internal water content. The addition of a surface water layer increases their effects on the spectral curve sharply, reminiscent of the typical strong absorption effects of water at 1500 and 2000nm. Kisevic et al. (2011) showed that leaf reflectance at $980 \mathrm{~nm}$ dropped approximately $50 \%$ from a wet leaf with the addition of a $7 \mathrm{~mm}$ thick water layer. Furthermore, a $2 \mathrm{~mm}$ thick water layer reduced reflectance beyond the $1500 \mathrm{~nm}$ mark to near zero.

Other common confounders are variations in leaf area index, orientation of leaves, canopy ground coverage, presence of non-leaf elements, areas of shadow and soil/litter surface reflectance (Blackburn 2007). However, many of these vary minimally within floating macrophyte stands. Floating macrophytes usually arrange their leaves horizontally, or near the water surface with a few leaf layers (Tsuchiya 1991). Only certain species have considerable three dimensional features. In addition, leaf area index variations are minimal compared to the range of terrestrial species (floating: $1.1-2 \mathrm{~m}^{2} \mathrm{~m}^{-2}$, terrestrial $3-13 \mathrm{~m}^{2} \mathrm{~m}^{-2}$ (Tsuchiya 1991)) and Jakubauskas et al. (2000) successfully assessed the density of Nuphar polysepala due to the high contrast between the vegetation and water background. Considering floating macrophytes can occur in simple arrangements, there are good prospects for extrapolating leaf level measurements to the canopy scale. However, further research is required to determine whether leaf level relationships are scalable to the canopy.

\subsection{Conclusions}

This study demonstrates that grouping various wetland vegetation types can achieve reasonable accuracy when estimating foliar pigment concentration. Avoiding the need to develop a semi-empirical relationship for each wetland vegetation type is an attractive approach, especially when computation simplicity is favored above overall accuracy. If accuracy is favored, then the correlations between vegetation indices and Chl-a, Chl-b, Car and Chl-a+b are generally improved by their separation. These findings suggest that floating macrophyte foliar biochemistry is subtly distinct from other vegetation types and these differences are primarily detectable along the red-edge. Hyperspectral observation of leaf level reflectance is a promising tool for assessing the foliar biochemistry of floating macrophytes since it is a quick and reliable 
1 method that considerably reduces the effort need to work in this already challenging

2 environment.

3

4 Acknowledgements

5

6 This research was supported by NSERC Discovery Grant RGPIN-386183 and CFI/ORF \#26492

7 to Dr. Yuhong He.

8

9

10 


\section{References}

Anderson JE. 1995. Spectral signature of wetland plants (350-900). USA Army Topographic Engineering Centre, Alexandria.

Asner GP. 1998. Biophysical and biochemical sources of variability in canopy reflectance. Remote Sensing of Environment. 64(3): 234-53.

Bartley GE, Scolnik PA. 1995. Plant carotenoids: pigments for photoprotection, visual attraction, and human health. The Plant Cell, 7(7): 1027-38.

Blackburn GA. 1998. Quantifying Chlorophylls and Caroteniods at Leaf and Canopy Scales: An Evaluation of Some Hyperspectral Approaches. Remote Sensing of Environment. 66(3): 273-85.

Blackburn GA. 2007. Wavelet decomposition of hyperspectral data: a novel approach to quantifying pigment concentrations in vegetation. International Journal of Remote Sensing. 28(12): 2831-55.

Broge NH, Mortensen JV. 2002. Deriving green crop area index and canopy chlorophyll density of winter wheat from spectral reflectance data. Remote Sensing of Environment. 81(1): 45-57.

Burlakova LE, Karatayev AY. 2007. The effect of invasive macrophytes and water level fluctuations on unionids in Texas impoundments. Hydrobiologia 586(1):291-302.

Catling PM, Mitrow G, Haber E, Posluszny U, Charlton WA. 2003. The biology of Canadian weeds. 124, Hydrocharis morsus-ranae L. Can Journal of Plant Science. 83(4): 1001-16.

Chapman L, Balirwa J, Bugenyi F, Chapman C, Crisman T. 2001 Wetlands of East Africa: Biodiversity, Exploitation and Policy Perspectives. In: Gopal B, Junk W, Davis J. Biodiversity in Wetlands: Assessment, Function and Conservation. Vol. 2. Leiden, The Netherlands: Backhuys Publishers. p 101-31.

Chen L, Huang JF, Wang FM, Tang YL. 2007. Comparison between backpropagation neural network and regression models for estimation of pigment content in rice leaves and panicles using hyperspectral data. International Journal of Remote Sensing. 28(26): 3457-78.

Coops N, Drury S, Smith ML, Martin M, Ollinger S. 2002. Comparison of green leaf eucalypt spectra using spectral decomposition. Australian Journal of Botany. 50(5): 567-76.

Darvishzadeh R, Skidmore A, Schlerf M, Atzberger C, Corsi F, Cho, M. 2008. LAI and chlorophyll estimation for a heterogeneous grassland using hyperspectral measurements. ISPRS Journal of Photogrammetry and Remote Sensing. 63(4): 409-26.

Dash J, Curran PJ. 2004. The MERIS terrestrial chlorophyll index. International Journal of Remote Sensing. 25(23): 5403-13. 
Daughtry CST, Walthall CL, Kim MS, Brown de Colstoun E, McMurtrey E, McMurtrey JE. 2000. Estimating corn leaf chlorophyll concentration from leaf and canopy reflectance. Remote Sensing of Environment. 74(2): 229-39.

Dawson T, North P, Plummer SE, Curran P. 2003. Forest ecosystem chlorophyll content: Implications for remotely sensed estimates of net primary productivity. International Journal of Remote Sensing. 24(3): 611-17.

Fang Z, Bouwkamp J, Solomos T. 1998. Chlorophyllase activities and chlorophyll degradation during leaf senescence in nonyellowing mutant and wild type of Phaseolus vulgaris L. Journal of Experimental Botany. 49(320): 503-10.

Field CB, Gamon JA, Penuelas J. 1994. Remote sensing of terrestrial photosynthesis. In: Schulze ED, Caldwell MM. Ecophysiology of Photosynthesis. Berlin, Germany: Springer-Verlag. p 51127.

Fletcher BJ, Gornall JL, Poyatos R, Press MC, Stoy PC, Huntley B, Baxter R, Phoenix GK. 2012. Photosynthesis and productivity in heterogeneous arctic tundra: consequences for ecosystem function of mixing vegetation types at stand edges. Journal of Ecology. 100(2): 44151.

Gamon JA, Serrano L, Surfus JS. 1997. The Photochemical Reflectance Index: An optical indicator of photosynthetic radiation use efficiency across species, functional types, and nutrient levels. Oecologia. 112(4): 492-501.

Gitelson AA, Gritz Y, Merzlyak MN. 2003. Relationships between leaf chlorophyll content and spectral reflectance and algorithms for non-destructive chlorophyll assessment in higher plant leaves. Journal of Plant Physiology. 160(3): 271-82.

Gitelson AA, Vina A, Ciganda V, Rundquist DC. 2005. Remote estimation of canopy chlorophyll content in crops. Geophysical Research Letters. 32(8): L08 403.1-L08 403.4.

Goel PK, Prasher SO, Landry JA, Patel RM, Viau AA, Miller JR. 2003. Estimation of crop biophysical parameters through airborne and field hyperspectral remote sensing. Transactions of the American Society of Agricultural Engineers. 46(4): 1235-46.

Guyot G, Baret F. 1988. Utilisation de la haute resolution spectrale pour suivre l'etat des couverts vegetaux. In: Proceedings of the Fourth International Colloquium on Spectral Signatures of Objects in Remote Sensing. ESA SP-287. Aussois, France. p. 279-86.

Hansen PM, Schjoerring JK. 2003. Reflectance measurement of canopy biomass and nitrogen status in wheat crops using normalized difference vegetation indices and partial least squares regression. Remote Sensing of Environment. 86(4): 542-53.

He Y, Mui A. 2010. Hyperspectral remote sensing of semi-arid grassland biochemical: scaling up from the leaf to the canopy level. Sensors. 10: 11072-11087. 
Jacquemoud S, Ustin SL, Verdebout J, Schmuck G, Andreoli G, Hosgood B. 1996. Estimating leaf biochemistry using the PROSPECT leaf optical properties model. Remote Sensing of Environment. 56(3): 194-202.

Jakubauskas M, Kindscher K, Fraser A, Debinski DN. 2000. Close-range remote sensing of aquatic macrophyte vegetation cover. International Journal of Remote Sensing. 21(18): 3533-38.

Kateregga E, Sterner T. 2007. Indicators for an invasive species: Water hyacinths in Lake Victoria. Ecological Indicators. 7(2): 362-70.

Kim MS, Daughtry CST, Chappelle EW, McMurtrey JE, Walthall CL. 1994. The use of high spectral resolution bands for estimating absorbed photosynthetically active radiation (APAR). In: Proceeding of the $6^{\text {th }}$ Symposium on Physical Measurements and Signatures in Remote Sensing. Jan. 17-21, 1994. Val D'Isere, France. p. 299-306.

Kisevic M, Smailbrgovic A, Gray KT, Andricevic R, Craft JD, Petrov V, Brajcic D, Dragicevic I. 2011. Spectral reflectance profile of Caulerpa racemosa var. cylindracea and Caulerpa taxifolia in the Adriatic Sea: Hyperspectral Image and Signal Processing: Evolution in Remote Sensing (WHISPERS). 2011 3rd Workshop. p. 1-4.

Lee K and Lunetta R. 1996. Wetland detection methods. In: Wetland and environmental application of GIS. Lyon JM, J., editor. New York: Lewis Publishers. p 249-284.

le Maire G, Francois C, Dufrene E. 2004. Towards universal broad leaf chlorophyll indices using PROSPECT simulated database and hyperspectral reflectance measurements. Remote Sensing of Environment. 89(1): 1-28.

Moran JA, Mitchell AK, Goodmanson G, Stockburger KA. 2000. Differentiation among effects of nitrogen fertilization treatments on conifer seedlings by foliar reflectance: a comparison of methods. Tree Physiology. 20(16): 1113-20.

Oppelt N, Mauser W. 2004. Hyperspectral monitoring of physiological parameters of wheat during a vegetation period using AVIS data. International Journal of Remote Sensing. 25(1): 145-59.

Osborne SL, Schepers JS, Francis DD, Schlemmer MR. 2002. Use of spectral radiance to estimate in-season biomass and grain yield in nitrogen- and water-stressed corn. Crop Science. 42(1): 165-71.

Outridge PM, Noller BN. 1991. Accumulation of toxic trace elements by freshwater vascular plants. Rev. Environ. Contam. Toxicol. 121, 1-63.

Palacios-Orueta A, Khanna S, Litago J, Whiting ML, Ustin SL. 2006. Assessment of NDVI and NDWI spectral indices using MODIS time series analysis and development of a new spectral index based on MODIS shortwave infrared bands. In: Proceedings of the $1^{\text {st }}$ International Ionference of Remote Sensing and Geoinformation Processing. Trier, Germany. p 207-9. 
Pierobon E, Bolpagni R, Bartoli M, Viaroli P. 2010. Net primary production and seasonal CO2 and CH4 fluxes in a trapa natans L. meadow. Journal of Limnology 69(2): 225-34.

Porra RJ, Thompson WA, Kreidemann PE. 1989. Determination of accurate extinction coefficients and simultaneous equations for assaying chlorophylls a and $b$ extracted with four different solvents: verification of the concentration of chlorophyll standards by atomic absorption spectrometry. BBA - Bioenergetics. 975 (3): 384-94.

Rahman MA, Hasegawa H. 2011. Aquatic arsenic: Phytoremediation using floating macrophytes. Chemosphere. 83(5): 633-46.

Richardson AD, Duigan SP, Berlyn GP. 2002. An evaluation of non-invasive methods to estimate foliar chlorophyll content. New Phytologist. 153(1): 185-94.

Robinson SA, Lovelock CE, Osmond CB. 1993. Wax as a mechanism for protection against photoinhibition: a study of Cotyledon orbiculata. Botanica Acta. 106(4). 307-12.

Rondeaux G, Steven M, Baret F. 1996. Optimization of soil-adjusted vegetation indices. Remote Sensing of Environment. 55(2): 95-107.

Rouse JW, Hass RW, Schell JA, Deering DW, Harlan JC. 1974. Monitoring the vernal advancement and retrogradation (greenwave effect) of natural vegetation. In: NASA/GSFCT Type III Final Report. Greenbelt, MD: NASA Goddard Space Flight Center. p 164.

Sampson PH, Mohammed GH, Zarco-Tejada PJ, Miller JR, Noland TL, Irving D, et al. 2000. The bioindicators of forest condition project: A physiological, remote sensing approach. Forest Chronicles. 76(6): 941-52.

Schroder P, Grosse W, Woermann D. 1986. Localization of thermo-osmotically active partitions in young leaves of Nuphar lutea. Journal of Experimental Botany. 37(10): 1450-61.

Sims DA, Gamon JA. 2002. Relationships between leaf pigment content and spectral reflectance across a wide range of species, leaf structures and developmental stages. Remote Sensing of Environment. 81(2-3): 337-54.

Slaton MR, Hunt ER, Smith WK. 2001. Estimating near-infrared leaf reflectance from structural characteristics. American Journal of Botany. 88(2): 278-84.

Thenkabail PS, Smith RB, De Pauw E. 2002. Evaluation of narrowband and broadband vegetation indices for determining optimal hyperspectral wavebands for agricultural crop characterization. Photogrammetric Engineering and Remote Sensing. 68(6): 607-21.

Tsuchiya T. 1991. Leaf life span of floating-leaved plants. Vegetatio. 97(2): 149-60.

Ustin SL, Smith MO, Jacquemoud S, Verstraete MM, Govaerts Y. 1998. Geo-botany: Vegetation mapping for earth sciences. In: Rencz AN. Manual of Remote Sensing.Hoboken, NJ: Wiley. p 189-248. 
2 Yao HB, Tian L. 2003. A genetic algorithm-based selective principal component analysis (GA-

3 SPCA) method for high-dimensional data feature extraction. IEEE Transactions on Geoscience 4 and Remote Sensing. 41(6): 1469-78.

5

6 Yoder BJ, Pettigrew-Crosby RE. 1995. Predicting nitrogen and chlorophyll content and

7 concentrations from reflectance spectra (400-2500 nm) at leaf and canopy scales. Remote

8 Sensing of Environment. 53(3): 199-211.

Zarco-Tejada PJ, Berjon A, Lopez-Lozano R, Miller JR, Martín P, Cachorro V, Gonzalez MR, 11 de Frutos A. 2005. Assessing vineyard condition with hyperspectral indices: Leaf and canopy

12 reflectance simulation in a row-structured discontinuous canopy. Remote Sensing of

13 Environment. 99(3): 271-87.

14

15 
Table 1. List of species sampled by vegetation type.

\begin{tabular}{|c|c|c|c|}
\hline Common Name & Scientific Name & Type & Sample Source \\
\hline Sweet Flag & Acorus calamus & GSR & Cranberry Marsh \\
\hline Canada Anemone & Anemone canadensis & HWF & \\
\hline Nodding Bur Marigold & Bidens cernua & HWF & \\
\hline Marsh Marigold & Caltha palustris & HWF & \\
\hline 3-Leaved Solomon's Seal & Maianthemum trifolium & HWF & \\
\hline Marsh Timothy & Muhlenbergia glomerta & GSR & \\
\hline Common Reed & Phragmites australis & GSR & \\
\hline Lady's Thumb & Polygonum persicaria & HWF & \\
\hline River Bullrush & Scripus fluviatilis & GSR & \\
\hline Beaked Sedge & Carex utriculata & GSR & \\
\hline Swamp Milk Weed & Asclepias incarnata & HWF & Rouge Park \\
\hline Common Milk Weed & Asclepias syriaca & HWF & \\
\hline Bog Arum * & Calla palustris & HWF & \\
\hline Swamp Thistle & Cirsium palustre & HWF & \\
\hline European Frog-bit * & Hydrocharis morsus-ranae & FM & \\
\hline Yellow Pond Lily & Nuphar variegatum & FM & \\
\hline Marsh Pepper Smartweed & Polygonum hydropiper & HWF & \\
\hline Pickerel Weed & Pontederia cordata & HWF & \\
\hline Broadleaf arrowhead & Sagittaria latifolia & HWF & \\
\hline Common Three Square & Scirpus pungens & GSR & \\
\hline Cup Plant * & Silphium perfoliatum & HWF & \\
\hline Greater Duckweed & Spirodela polyrhiza & FM & \\
\hline Kidney-Leaved Violet & Viola renifolia & HWF & \\
\hline Northern Bugleweed & Lycopus uniforus & HWF & \\
\hline Bog Aster & Aster nemoralis & HWF & \\
\hline Northern Bog Goldenrod & Solidago uliginosa & HWF & \\
\hline Common Burreed & Sparganium eurycarpum & GSR & \\
\hline Floating Water Lily & Nymphaea odorata & FM & Cranberry Marsh/ \\
\hline Water Smart Weed ** & Polygonum amphibium & FM & Rouge Park \\
\hline Cattail & Typha latifola & GSR & \\
\hline Purple Loosestrife & Lythrum salicaria & HWF & \\
\hline Fairy Moss & Azolla filiculoides & FM & Plant Nursery \\
\hline Water Hyacinth & Eichhoria crassipes & FM & \\
\hline Columbia Watermeal & Wolffia arrhiza & FM & \\
\hline SpadderDock & Nuphar luteum & FM & \\
\hline Yellow Floating Heart & Nymphoides peltata & FM & \\
\hline Bog Bean & Menyanthes trifoliata & HWF & \\
\hline Water Lettuce & Pistia stratiotes & FM & \\
\hline Common Salvinia & Salvinia molesta & FM & \\
\hline
\end{tabular}

* Significant leaf color variation was present due to leaf age. Samples were taken for new and mature leaves. ** Polygonum amphibium is a heterophyllous species with both floating and aerial leaf forms with different morphology and coloration. Samples were taken for both the floating and aerial leaves. 
Table 2. Equations for the vegetation indices investigated by this study $\left(\mathrm{R}_{\lambda}\right.$ indicates the reflectance of the band centered on wavelength $\lambda$ )

\begin{tabular}{lcl}
\hline Index & Formula & Reference \\
\hline CARI & {$\left[\left(R_{700}-R_{670}\right)-0.2 *\left(R_{700}-R_{550}\right)\right]$} & Kim et al. (1994) \\
CI-Red & $\left(R_{780} / R_{710}\right)-1$ & Gitelson et al. (2003) \\
CI-Green & $\left(R_{780} / R_{550}\right)-1$ & Gitelson et al. (2003) \\
DD & {$\left[\left(R_{750}-R_{720}\right)-\left(R_{700}-R_{670}\right)\right]$} & le Maire et al. (2004) \\
HNDVI & $\left(R_{827}-R_{668}\right) /\left(R_{827}+R_{668}\right)$ & Oppelt and Mauser (2004) \\
REP & $700+40 \frac{\left(R_{670}+R_{780}\right) / 2-R_{700}}{R_{740}-R_{700}}$ & Guyot and Baret (1988) \\
& $\left(R_{700}-R_{670}\right)-0.2 *\left(R_{700}-R_{550}\right) *\left(R_{700} / R_{670}\right)$ & Daughtry et al. (2000) \\
MCARI & {$\left[\left(R_{750}-R_{710}\right) /\left(R_{710}-R_{680}\right)\right]$} & Dash and Curran (2004) \\
MTCI & $\left(R_{820}-R_{670}\right) /\left(R_{820}+R_{670}\right)$ & Rouse et al. (1974) \\
NDVI & $c 0 s^{-1}\left(\frac{a^{2}+b^{2}+c^{2}}{2 a b}\right)$ & Palacios-Orueta et al. \\
NGAI & $a=R_{820}-R_{554}$ & (2006) \\
& $b=R_{977}-R_{554}$ & \\
& $c=R_{977}-R_{820}$ & \\
& $\left(R_{531}-R_{570}\right) /\left(R_{531}+R_{570}\right)$ & \\
OSAVI & $\left(R_{750} / R_{720}\right)-1$ & Rondeaux et al. 1996 \\
PRI & & Gamon et al. (1997) \\
R-M & $1.16 *\left(R_{800}-R_{670}\right) /\left(R_{80}+R_{670}+0.16\right)$ &
\end{tabular}

Table 3. Foliar pigment concentrations (ug/mg) derived from sample extracts.

\begin{tabular}{llrrrr}
\hline Type & Pigment & Min & Max & Mean & St.Dev \\
\hline ALL & Chl-a & 0.017 & 0.306 & 0.157 & 0.068 \\
& Chl-b & 0.008 & 0.228 & 0.057 & 0.039 \\
& Car & 0.006 & 0.099 & 0.052 & 0.022 \\
& Chl-a+b & 0.025 & 0.512 & 0.214 & 0.104 \\
FM & Chl-a & 0.071 & 0.254 & 0.135 & 0.045 \\
& Chl-b & 0.017 & 0.083 & 0.045 & 0.015 \\
& Car & 0.022 & 0.074 & 0.046 & 0.016 \\
& Chl-a+b & 0.088 & 0.337 & 0.179 & 0.060 \\
GSR & Chl-a & 0.048 & 0.306 & 0.164 & 0.104 \\
& Chl-b & 0.017 & 0.124 & 0.078 & 0.076 \\
& Car & 0.015 & 0.099 & 0.053 & 0.033 \\
& Chl-a+b & 0.065 & 0.512 & 0.242 & 0.176 \\
HWF & Chl-a & 0.016 & 0.291 & 0.172 & 0.064 \\
& Chl-b & 0.008 & 0.106 & 0.058 & 0.025 \\
& Car & 0.005 & 0.095 & 0.057 & 0.021 \\
& Chl-a+b & 0.025 & 0.398 & 0.23 & 0.089 \\
\hline
\end{tabular}


Table 4. Regression results of the three fitted function for Chl-a concentration.

\begin{tabular}{|c|c|c|c|c|}
\hline \multirow{2}{*}{ Type } & \multirow{2}{*}{ Index } & \multicolumn{3}{|c|}{$\mathrm{R}^{2}$} \\
\hline & & Linear & Polynomial & $\log$ \\
\hline \multirow[t]{13}{*}{ ALL } & CARI & 0.440 & 0.443 & 0.413 \\
\hline & CI-Red & 0.633 & 0.644 & 0.484 \\
\hline & CI-Green & 0.443 & 0.452 & 0.393 \\
\hline & DD & 0.574 & 0.576 & 0.472 \\
\hline & HNDVI & 0.035 & 0.147 & 0.058 \\
\hline & REP & 0.511 & 0.512 & 0.420 \\
\hline & MCARI & 0.381 & 0.386 & 0.351 \\
\hline & MTCI & 0.615 & 0.635 & 0.455 \\
\hline & NDVI & 0.029 & 0.132 & 0.050 \\
\hline & NGAI & 0.170 & 0.193 & 0.145 \\
\hline & OSAVI & 0.080 & 0.141 & 0.084 \\
\hline & PRI & 0.070 & 0.083 & 0.044 \\
\hline & R-M & 0.612 & 0.640 & 0.453 \\
\hline \multirow[t]{13}{*}{ FM } & CARI & 0.705 & 0.706 & 0.652 \\
\hline & CI-Red & 0.808 & 0.838 & 0.824 \\
\hline & CI-Green & 0.676 & 0.691 & 0.693 \\
\hline & DD & 0.730 & 0.779 & 0.772 \\
\hline & HNDVI & 0.258 & 0.401 & 0.345 \\
\hline & REP & 0.542 & 0.662 & 0.624 \\
\hline & MCARI & 0.294 & 0.323 & 0.229 \\
\hline & MTCI & 0.769 & 0.787 & 0.774 \\
\hline & NDVI & 0.251 & 0.366 & 0.327 \\
\hline & NGAI & 0.266 & 0.448 & 0.354 \\
\hline & OSAVI & 0.313 & 0.451 & 0.399 \\
\hline & PRI & 0.055 & 0.097 & 0.035 \\
\hline & R-M & 0.753 & 0.808 & 0.797 \\
\hline \multirow[t]{13}{*}{ GSR } & CARI & 0.277 & 0.281 & 0.243 \\
\hline & CI-Red & 0.641 & 0.647 & 0.588 \\
\hline & CI-Green & 0.466 & 0.467 & 0.439 \\
\hline & DD & 0.572 & 0.575 & 0.524 \\
\hline & HNDVI & 0.131 & 0.211 & 0.106 \\
\hline & REP & 0.561 & 0.562 & 0.518 \\
\hline & MCARI & 0.309 & 0.309 & 0.274 \\
\hline & MTCI & 0.629 & 0.630 & 0.583 \\
\hline & NDVI & 0.111 & 0.215 & 0.086 \\
\hline & NGAI & 0.201 & 0.203 & 0.199 \\
\hline & OSAVI & 0.278 & 0.344 & 0.239 \\
\hline & PRI & 0.263 & 0.269 & 0.240 \\
\hline & R-M & 0.702 & 0.711 & 0.643 \\
\hline \multirow[t]{13}{*}{ HWF } & CARI & 0.729 & 0.752 & 0.567 \\
\hline & CI-Red & 0.735 & 0.778 & 0.474 \\
\hline & CI-Green & 0.697 & 0.747 & 0.438 \\
\hline & DD & 0.723 & 0.724 & 0.528 \\
\hline & HNDVI & 0.044 & 0.057 & 0.034 \\
\hline & REP & 0.738 & 0.746 & 0.539 \\
\hline & MCARI & 0.737 & 0.747 & 0.604 \\
\hline & MTCI & 0.744 & 0.802 & 0.46 \\
\hline & NDVI & 0.039 & 0.045 & 0.025 \\
\hline & NGAI & 0.315 & 0.321 & 0.218 \\
\hline & OSAVI & 0.003 & 0.012 & 0.001 \\
\hline & PRI & 0.054 & 0.056 & 0.037 \\
\hline & R-M & 0.739 & 0.767 & 0.491 \\
\hline
\end{tabular}


Table 5. Regression results of the top performing fitted functions

\begin{tabular}{llllll}
\hline Type & Pigment & Index & $\mathrm{R}^{2}$ & cvRMSE & Fitted Equation \\
\hline ALL & Chl-a & CI-Red & 0.63 & 0.235 & $0.45+7.34 * \mathrm{X}$ \\
& Chl-b & R-M & 0.64 & 0.230 & $0.33+4.98 * \mathrm{X}$ \\
& Car & CI-Red & 0.51 & 0.273 & $0.55+20.02 * \mathrm{X}$ \\
& Chl-a+b & R-M & 0.66 & 0.224 & $0.21+1.88 * \mathrm{X}$ \\
FM & Chl-a & CI-Red & 0.81 & 0.170 & $-0.12+11.83 * \mathrm{X}$ \\
& Chl-b & CI-Red & 0.76 & 0.190 & $-0.03+33.83 * \mathrm{X}$ \\
& Car & CI-Red & 0.73 & 0.200 & $-0.03+32.48 * \mathrm{X}$ \\
& Chl-a+b & CI-Red & 0.80 & 0.174 & $-0.11+8.84 * \mathrm{X}$ \\
GSR & Chl-a & R-M & 0.70 & 0.176 & $0.45+2.24 * \mathrm{X}$ \\
& Chl-b & R-M & 0.55 & 0.215 & $0.52+5.44 * \mathrm{X}$ \\
& Car & R-M & 0.70 & 0.176 & $0.44+7.03 * \mathrm{X}$ \\
& Chl-a+b & R-M & 0.67 & 0.186 & $0.47+1.57 * \mathrm{X}$ \\
& Chl-a & MTCI & 0.74 & 0.217 & $0.00+12.17 * \mathrm{X}$ \\
& Chl-b & MTCI & 0.83 & 0.176 & $0.19+32.73 * \mathrm{X}$ \\
& Car & MCARI & 0.54 & 0.479 & $1.21-12.49 * \mathrm{X}$ \\
& Chl-a+b & MTCI & 0.77 & 0.203 & $0.03+8.97 * \mathrm{X}$ \\
\hline
\end{tabular}




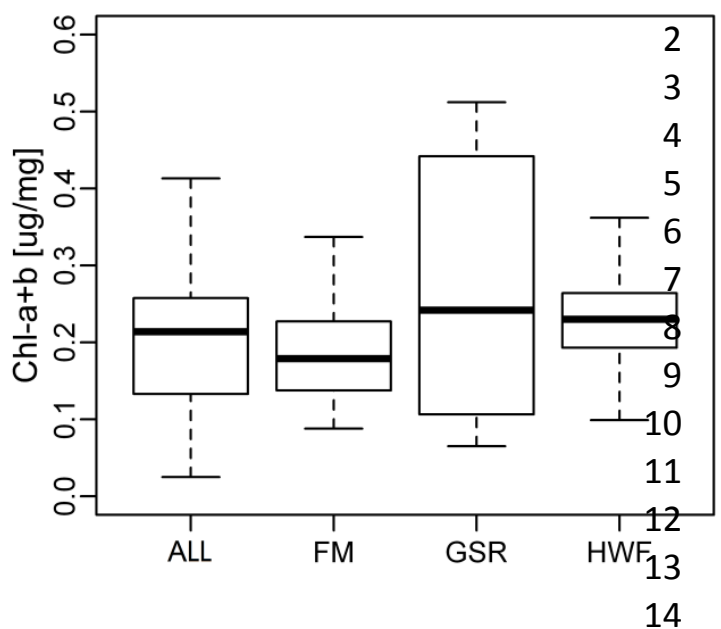

Figure 1. Boxplots of Chl-a+b concentration per vegetation type. Dark line is the mean.

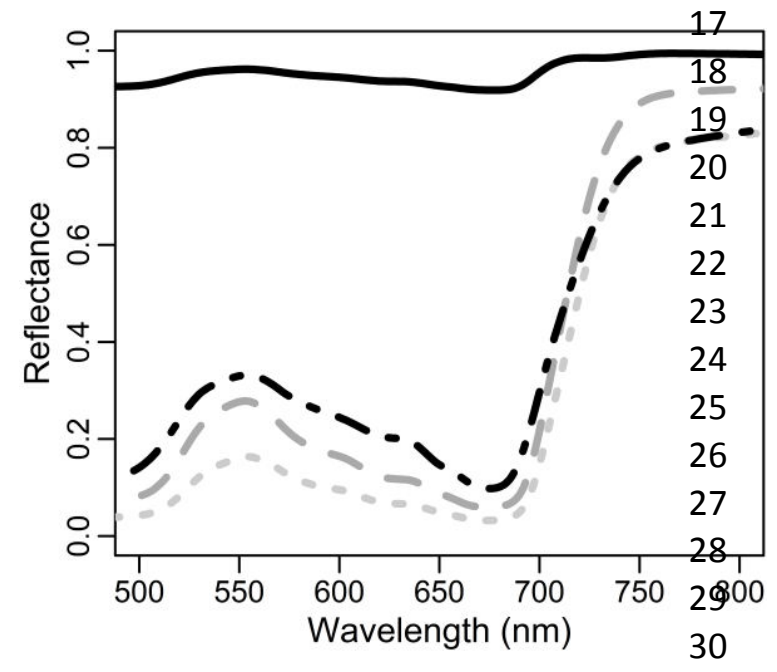

Figure 2. Reflectance of Common Burred (dot-dash line), Marsh Pepper Smartweed (dashed line), Water Smartweed (dotted line) and ALL standard deviation + 0.9 (solid line) 

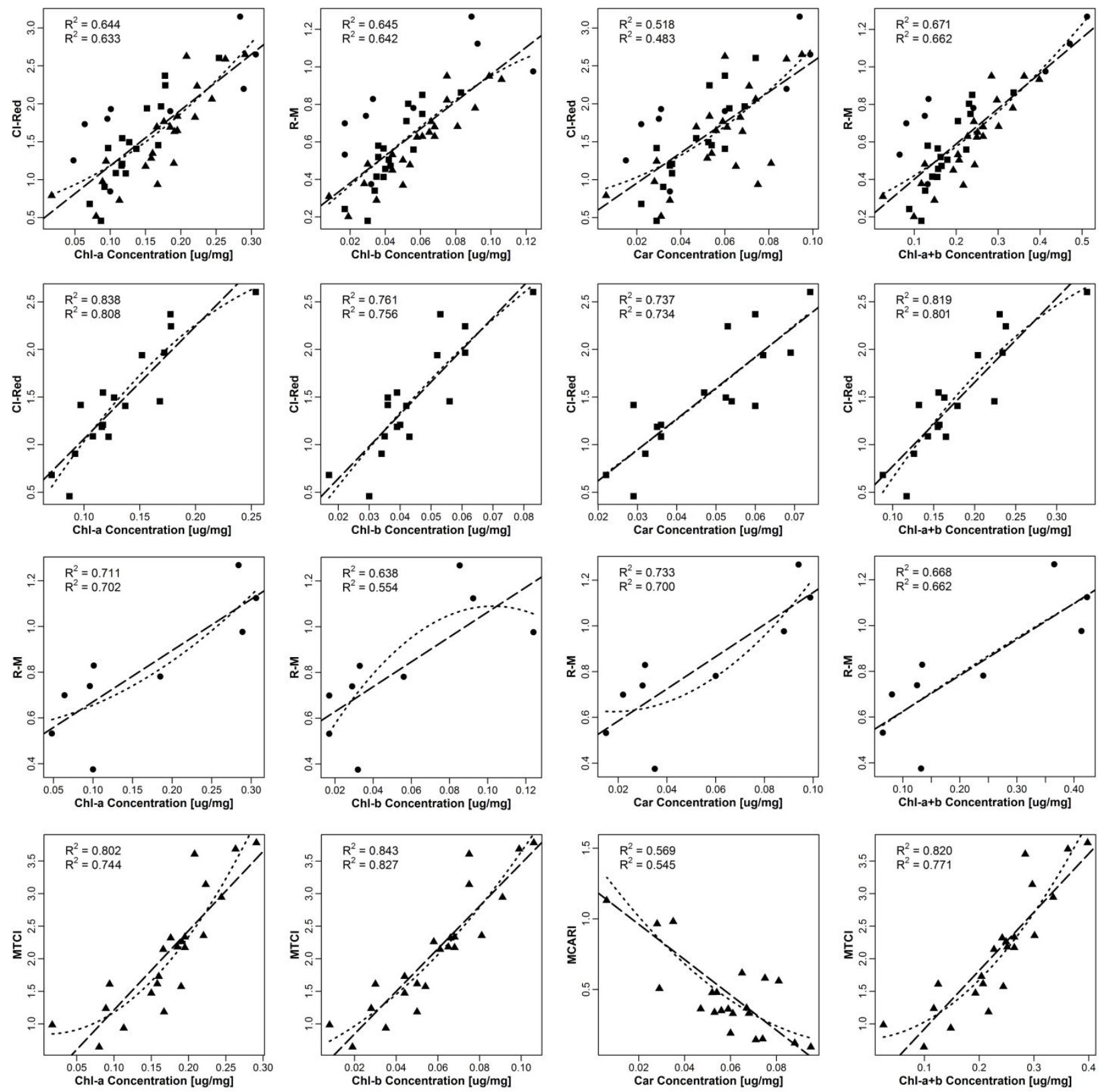

Figure 3. Predicted relationship between best performing vegetation indices for four vegetation types (a) ALL (top row), (b) FM (second row), (c) GSR (third row) and (d) HWF (bottom row) against foliar pigment concentrations, (i) Chl-a (1st column), (ii) Chl-b (2nd column), (iii) Car (3rd column) and (iv) Chl-a+b (4th column). $\mathrm{R}^{2}$ values in top left corner are for the seconddegree polynomial (top) and linear fitted function (bottom). 
1

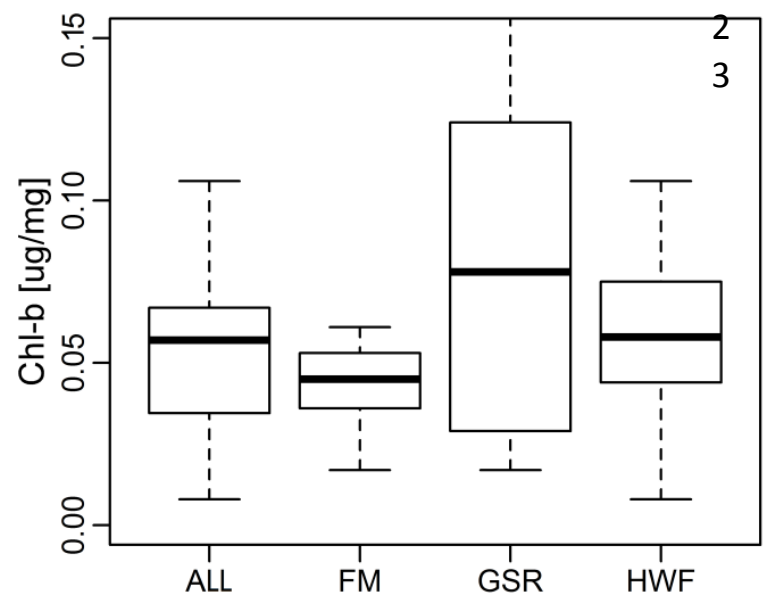

Figure 4. Boxplots of Chl-b concentration per vegetation type. Bold line is the mean 